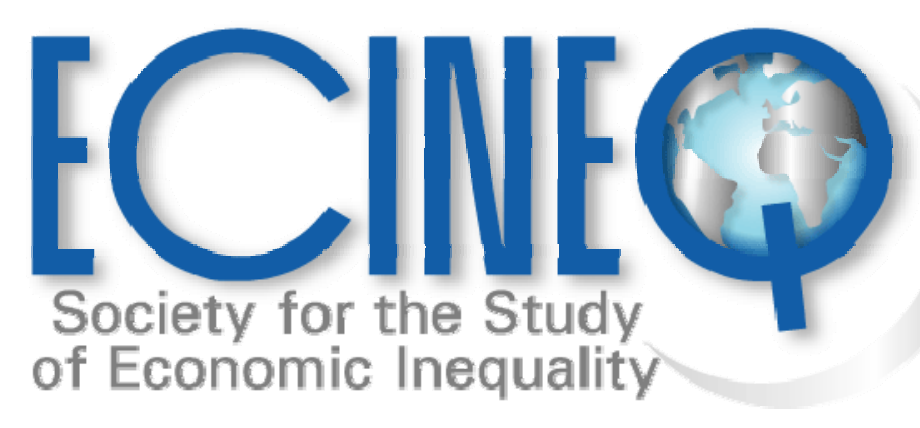

Working Paper Series

Inflation, unemployment, labor force change in the USA

Ivan O. Kitov

ECINEQ WP $2006-28$ 


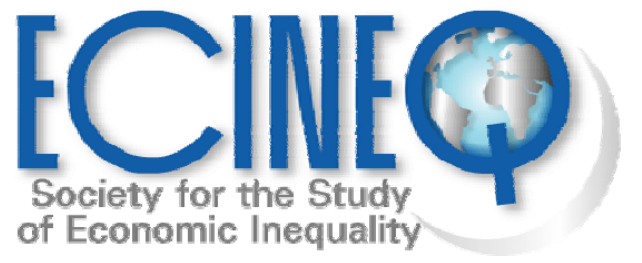

ECINEQ 2006-28

March 2006

www.ecineq.org

\title{
Inflation, unemployment, labor force change in the USA
}

\author{
Ivan O. Kitov ${ }^{*}$ \\ Russian Academy of Sciences
}

\begin{abstract}
Inflation in the USA for the period between 1960 and 2004 is studied in the framework of evident rigidity of personal income distribution normalized to the total nominal GDP. Inflation is found to be a mechanism, which counters changes in the relative incomes induced by economic growth and population changes - both in number and age structure. A model is developed linking the measured inflation (consumer price index or GDP deflator), unemployment and change in labor force. During the last twenty-five years, unemployment in the USA has been a lagged linear function of inflation. In turn, inflation has also been a lagged linear function of relative change in labor force with time. The lag is currently three years.

Only a small decrease in labor force participation rate is currently observed in contrast to a strong increase between 1965 and 1990. According to the indicated relationship, the well-known stagflation period clearly resulted from the lag: the sharp increase in inflation coincided in time with the high unemployment induced by the high inflation period two years before. One can predict the unemployment rate in the USA in the following two years within the accuracy of inflation measurements. For example, the end of 2005 is a pivot point from a period of decreasing unemployment to one of moderate growth from $5 \%$ in 2005 to $6 \%$ in the middle of 2008. Starting in 1960, cumulative values of the observed and the model predicted unemployment are in agreement with the lag between inflation and unemployment.

Inflation is defined by a lagged linear function of rate of change in labor force. The observed and predicted inflation almost coincide for the last forty years of annual measurement values, smoothed by a fiveyear wide moving window curves and as cumulative curves as well. Deviation of the curves before 1960 can be explained by a degraded accuracy of the measurements. A severe decrease in the rate of change of labor force is expected after 2010. This drop can potentially induce a long-term deflationary period. The same effect has been observed for Japan starting in 1990.

There are numerous implications of the results for monetary and social policy-makers. The most important is an absence of any means to control inflation and economic growth except though a reasonable labor policy. In addition, some urgent measures are necessary to prevent the start of a deflationary period in 2010-2012.
\end{abstract}

JEL classification: E3, E6, J21

Key words: inflation, unemployment, labor force, USA, time series models

\footnotetext{
* Contact details: VIC, P.O. Box 1250, Vienna 1400, Austria; email - ikitov@mail.ru
} 


\section{Introduction}

There is a principal assumption of the existence of a tight link between inflation and unemployment known as the Phillips curve. The concept of the Phillips curve serves as a basis for many macroeconomic models and business cycle theories. There is no “completely satisfactory explanation” [Mankiw, 2000] of this virtual tradeoff, however. Existing models meet severe problems to explain some outstanding features of the presumed tradeoff between inflation and unemployment, such as, for example, stagflation and disinflation accompanying decreasing unemployment, without using some exotic exogenous forces or shocks. This lack of proof or demonstration of even a weak empirical confirmation of the relationship does not prevent central bankers and monetary economists from adhering to its usage in practice [Mankiw, 2000]. Hence, any clear explanation of the existence of tradeoff between inflation and unemployment, or its absence, in which case the bankers, monetary policy-makers and economists are wrong in their unproven assumption, is of great value. We show below that there is no tradeoff between simultaneous readings of unemployment and inflation. The period between 1990 and 2010 is characterized by just minor changes of the studied variables. This is what makes current monetary policy so "successful”. There are some challenges arising in near future, however.

In the first section, we argue that the presumed relationship between inflation and unemployment is just a simple lagged linear function with a positive coefficient. This effectively means that, if accordingly modified, the Phillips curve is an upward-sloping function with a coefficient close to one, but where unemployment does not affect inflation.

If unemployment in the USA is a lagged linear function of inflation, it is important to find the potential forces driving the inflation itself. The macroeconomic model developed by Kitov [2005a,b] provides a consistent framework for such an analysis. The two principal findings of the model are as follows: 1) real economic growth in the USA depends only on the attained value of real GDP per capita and the relative change in the number of nine-year-olds in the population; 2) the personal income distribution (PID) is very rigid relative to real economic growth and inflation. The first finding allows effective decoupling of the study of inflation from the economic 
development - the real economic growth in terms of GDP per capita does not depend on inflation and vice versa. The second finding leads to a simple idea that inflation causes only nominal income changes but not relative changes in distribution of income, i.e. a given portion of population always has a predefined portion of the total nominal GDP. Thus, any successful personal attempt to occupy a position with a larger income that is already occupied causes some forces directed to return the person to her/his original relative position, i.e. stretching the PID and inducing inflation. (One can imagine a climb by a downward running escalator - all efforts to climb up result in the same position relative to the ground but changing relative to the escalator itself. Similarly, persons enjoy a higher nominal income but the same relative place in the PID.)

Labor force change is a potential candidate for describing the process of personal attempts to advance in the PID. The second section describes the process and provides empirical facts supporting this concept. One of the findings is that the labor force change leads inflation by two years. Therefore, this causality principle excludes the current inflation value from being controlled by some contemporary means including monetary ones. One cannot exclude "insane” behavior of some monetary authorities, however, such as flooding an economy with money. This is not the case for the USA, but it happens sometimes in countries in transition. In our opinion, the driving force for such "strange" behavior is the redistribution of personal incomes in a new way after failure of the old economic and social organization. One can observe a fast evolution of PID in former socialist countries during the last 15 years from a truncated "socialist" version to a wide “capitalist” one.

Having in the first two sections demonstrated causal relationships between unemployment and inflation and between inflation and labor force change, one can easily apply the same methodology to the dependence of unemployment on labor force and inflation. The third section provides some details of this analysis and shows that the observed unemployment in the USA is a lagged linear function of labor force change and inflation. Thus one can consider unemployment to be a rest of those who tried to enter the PID at higher incomes and who induced inflation. Unemployment consists of people who have failed to change their income positions and correspondingly did not increase inflation. All migrationary processes inside the PID have their characteristic times 
inducing observed delays between the acting forces and outcomes. These processes are out of the scope of the study and present a challenge to future investigation.

We also discuss briefly some potential outcomes and some directions for the future study and application. We insist that modern business cycle theories should be accordingly modified and more efforts should be applied to study the processes responsible for the propagation of labor force changes through the real economy.

\section{Unemployment and inflation}

A standard way of presenting the relationship between inflation (INF) and unemployment $(U E)$ is a scatter plot of simultaneous measurements. Unemployment is measured by the US Census Bureau (CB) during the Current Population Survey (CPS) [US CB, 2002] and is published monthly by the Bureau of Labor Statistics (US BLS) [US BLS, 2005a]. Unemployment is not an accurately measured variable as described by the CB.

Inflation is an even more obscure variable. There are numerous definitions of inflation resulting in different values. The principal problem for any of these definitions is the estimation of the price of new products. In the world of goods and services renewed at accelerating rate, there is no reliable procedure to estimate the price change for new goods even if they are substitutes for some old goods. Thus, the concept of inflation and hence the concept of real economic growth is partly artificial and bears a flavor of subjective judgment. All these problems make the finding of any strict relationship between the variables not only difficult but also a slightly unreliable task. Partly because of these problems, the original Phillips curve implying the existence of a well defined relationship is currently under strong doubt and may be replaced by a general assumption concerning the possibility to influence inflation and unemployment by monetary means [Mankiw, 2000].

We develop a new approach based on dynamic representations of the studied variables (including smoothed and cumulative values) and their evolution in time. Instead of a straightforward plotting of inflation against unemployment and the construction of a standard scatter plot, one can plot both variables as a function of time and check if the curves have some resemblance. Figure 1 shows the measured unemployment in the USA for the period between 1948 and 2004 along with two inflation estimates - annual CPI 
values (not seasonally adjusted, NSA) published by the Bureau of Labor Statistics [2005b] and annual GDP deflator values published by the Bureau of Economic Analysis of the Department of Commerce [2005]. The original unemployment readings are corrected by $-3 \%$ in order to equalize values of the variables during the last twenty years.

One can observe a clear overall similarity of the inflation curves in spite of some small variations in amplitude and years of peak values, especially between 1975 and 1990. As expected, the CPI curve is consistently above the GDP deflator one. Surprisingly, the unemployment curve repeats the shape of those for inflation. The best correlation is observed during the last twenty years.

The means synchronizing the peaks and troughs in the curves is very simple - the unemployment curve is shifted by 2.5 years back in time. This time shift contains two years of actual shift and half a year of artificial shift. For the latter shift the annual readings of unemployment are obtained by averaging corresponding monthly values over the year. This effectively makes the unemployment values to be associated with the center of the given year rather than with the end. Conversely, the inflation values are cumulative ones and correspond to the last day of the year, which is why the artificial half-year shift arises.

Neglecting some small variation in peak and trough timings, one can conclude that the observed inflation is potentially a leading variable relative to the measured unemployment, or that the unemployment is a lagged linear function of the inflation in the USA. One of the immediate implications of this observation is a possibility for predicting unemployment evolution during the two years following from a measured inflation value. For example, the decreased unemployment consistently observed during the last two years is just a short-term feature. The recent evolution of the inflation indicates that the year 2006 is a pivot point to an unemployment increase from the current $5 \%$ to $6 \%$ in the middle of 2008 . Further development of unemployment can be easily predicted by the future inflation.

Figures 2 and 3 present two modified Phillips curves. The original unemployment values are replaced with those two years later, i.e. those synchronized with the inflation. The curve in Figure 2 corresponds to the period between 1960 and 2004 and that in Figure 3 to the last twenty years. The modified Phillips curves illustrate a simple linear 
relationship between inflation and unemployment. There is no conventional downwardsloping Phillips curve so important for any monetary policy using tradeoff between inflation and unemployment. On the other hand, there is also no vague and stylized relationship, which is often used in current theory and practice as a substitute for the original Phillips curve [Ball\&Mankiw, 2002]. In reality, current unemployment rate depends on inflation observed two years ago.

One of the prominent effects of the unemployment lag behind inflation is stagflation. Actual observations of unemployment and inflation in the USA have never given a better example of a contradiction to the conventional Phillips curve: one cannot expect unemployment growth when inflation rockets up. Let us study the period between 1970 and 1990 in more detail as displayed in Figure 4. We know now that the unemployment repeats the inflation path with a delay. In 1972, inflation starts its first growth session. The unemployment curve still follows the path that the inflation passed two years previously. In 1975, the inflation curve reaches its local peak of about $10 \%$. A year before, in 1974 (there is some variation of the lag induced by the measurement accuracy and the variable used - GDP deflator or CPI), the unemployment "unexpectedly" jumped from its modest level below $6 \%$ to a value well above $8 \%$. The first session of stagflation had happened. Nobody was worried too much by this first lesson. The stagflation period was very short. In 1976, the inflation dropped and unemployment showed some downward motion. The next session, however, was much more of concern. Starting in 1977, the inflation curve (GDP deflator) demonstrates a fiveyear long monotonic increase from $6 \%$ to $9.5 \%$. This is two years longer than the previous period of growth. The unemployment curve stagnates at the start, but then shows a faster growth. A two-year long period of stagflation begins in 1979. By chance, the Federal Reserve chairman P.Volker announced a new monetary policy exactly at the same time. The growth in unemployment was attributed to the effectiveness of the new monetary technique according to the original Phillips curve assumption. The observed inflation started to drop in 1981 (CPI) or 1982 (GDP deflator). The drop was interpreted to be a result of the new monetary policy targeted to control inflation. The unemployment continued to grow for two more years in total agreement with the conventional Phillips curve but also in agreement with the two-year delay we have just shown. The new policy 
was wrongly considered to be the cause, which forced things to behave as prescribed by the Phillips curve during this short period. The next "strange" deviation from canonic behavior appeared about ten years later - in the early 1990s. One can see, however, that the unemployment curve just follows its prescribed path. In essence, inflation cannot depend on unemployment. Inflation leads unemployment by two years.

There are numerous potential implications of this linear lagged relationship between unemployment and inflation in economic theory and monetary practice. Here we would just like to stress that there is no monetary policy to "push inflation and unemployment in opposite directions” [Ball\&Mankiw, 2002] because the variables are following their own paths with inflation leading by two years. Below we also demonstrate that there is no feasible monetary policy to control the current value of inflation because the latter depends solely on labor force changes in past, at least in the USA. Hence, neither unemployment nor inflation is currently in hands of policy makers.

\section{Inflation and labor force}

In the previous section, we have learned that unemployment is a lagged linear function of inflation in the USA during the last twenty years. This observation, however, does not reveal the real cause of inflation itself. What is the perpetual source of inflation that forces economists around the world to study phenomena such as inflation persistence? Below we attempt to explain inflation as the effect of a single process - labor force $(L F)$ change.

Labor force is a measurable variable equal to the sum of employed persons and those who currently want to have a paid job or its equivalent. In the USA, this definition implies that people announce their current status during the Current Population Surveys. Because of a limited size of the survey, accuracy of the measurements is also limited and fluctuations in the obtained values are common. Sampling and nonsampling errors reach $0.4 \%$ to $0.6 \%$, i.e. there is no statistical difference between the labor force participation rate values $66 \%$ and $66.8 \%$, if the published value is $66.4 \%$ [US BLS, 2006]. For unemployment, this uncertainty is of $0.2 \%$ to $0.4 \%$.

Despite a relatively low reliability in the monthly readings, the long-term observations allow a better representation of the labor force behavior in the USA. Annual 
time series of the labor force participation rate estimates for the period between 1948 and 2004 is presented in Figure 5. The observed behavior is characterized by a long period of intensive growth from about 58.5\% in 1965 to $67 \%$ in 1990 . There was a short period of very weak growth between 1979 and 1983, however. A decade of decelerating growth started around 1990. In 2000, a period of a relatively fast participation factor decrease began.

Figure 6 presents the US labor force growth rate $(d L F / L F)$ for the same period. The current growth rate is about 0.01. This value is lower than the growth rate of the working age population itself (around 0.015), which effectively makes the growth rate of the labor force participation rate negative (see Figure 5). The mean value of the labor force change for the entire studied period is 0.016 . So, one can distinguish the periods of elevated growth rate and low growth rate compared to this mean value. The period between 1965 and 1990 is characterized by a consistently elevated labor force growth rate.

Why do these fluctuations around the average value of the labor force growth rate not affect the personal income distribution? How does the rigid PID accommodate the new labor force? Our working assumption is that the accommodation process is similar to the process when one inflates a balloon - the air influx creates overpressure inside the balloon and forces its wall to stretch elastically. The larger the overpressure, the large the stretch. Similarly, the labor force newcomers obtain some new paid or unpaid positions inside the PID and effectively increase "overpressure” in the income bins (the standard CB income bin is \$2500) (i.e. too many people have the same income what induces competition leading to stratification). To accommodate this overpressure and to return to some normal "pressure” or population density the income bins have to stretch elastically. The stretch depends on the elasticity of the PID. The stretch process is called inflation in economics because the new nominal PID is characterized by a larger total income translated into growth of consumer prices. The elasticity can be measured in the standard physical analogue as a coefficient of a linear relationship between the force (labor force growth rate) and deformation (inflation).

The reason for the participation factor change may be of economic, social, demographic, psychological or some other character. An important aspect, however, is 
that the observed labor force change in the USA leads inflation by two years. This finding invalidates many of the current economic assumptions and models. For example, no monetary policy can control current inflation because the latter is a sole function of labor force change two years beforehand. Since unemployment is a lagged function of inflation, it has also to be driven by the labor force change, but with a larger lag.

Figure 7 illustrates the linear relationship between inflation (GDP deflator) and the labor force change rate in the USA for the period between 1960 and 2004. The readings of the labor force change rate are shifted by two and a half years ahead in time to synchronize the observed peaks and troughs with those of inflation in 1975 and 1984. Due to uncertainty in the labor force (and inflation) measurements the most reliable readings correspond to the largest changes, as described but the US BLS [2006].

The predicted and measured values of inflation are consistent throughout the whole period. The predicted values are obtained by a linear relationship displayed in the right-bottom part of the Figure. We intentionally distinguish two constants in the relationship. The first constant is $0.06(6 \%)$ and corresponds to the mean inflation observed during the entire period between 1948 and 2004. The second constant is found by fitting the measured and predicted cumulative curves as discussed below. Its value is 0.0224. In the case of a constant labor force change rate of 0.0224 per annum, there would be no inflation change. The sensitivity factor or elasticity is 4 . This implies that one per cent labor force change leads to four per cent inflation change.

The labor force change can be split into two components: an extensive component and an intensive one. The extensive component is associated with the growth of working age population. This growth was about 1.4\% per year in average between 1948 and 2004. If the extensive component of the labor force does not change, inflation is defined only by the second component - the change in labor force participation rate.

The most prominent feature is a complete coincidence of the peak values in time and in amplitude. Some short-term fluctuations in labor force and corresponding deviations of the predicted inflation are potentially induced by two factors: the accuracy of the labor force measurements and the corrections of the population estimates implemented by the US Census Bureau in census years. Due to a four times lower amplitude of the labor force change rate compared to that of the inflation one can expect 
that even small errors in the labor force estimates result in notable discrepancies between the predicted and observed inflation. These errors are visible in fluctuations between the census years. The fluctuations are characterized by much higher amplitude and are induced by the large-amplitude corrections (more than $1 \%$ ) in the working age population estimates. These corrections are especially large in 1963, 1993, and 2003 (because of the 2.5 year shift) and result in an almost four per cent change in the predicted curve due to the elasticity value.

There are some standard tools to reduce the measurement noise effects if they of a random character - apply a long-period filter or use cumulative values. The highfrequency uncorrelated noise is usually suppressed by averaging over a longer period. Figure 8 presents two smoothed inflation curves - the measured and predicted one. The smoothing was accomplished by averaging using a 7-year moving windows (seven years before given year) with a one-year step. The predicted curve is shifted by 2.5 years ahead in order to fit the actual inflation pick near 1978. The original (unshifted) prediction curve is also shown for illustration of the synchronization procedure. The effects of the population corrections are also clear.

Figure 9 displays the observed and predicted cumulative curves of inflation starting in 1965. The predicted cumulative curve is obtained by a progressive summation of values from 1963 and is also advanced ahead by 2.5 years. There is an almost complete coincidence of the cumulative curves for the whole period. The only small deviation occurred around 1993 and corresponds to a sharp drop of the labor force growth rate induced by the baseline working age population correction. The cumulative predicted curve is very sensitive to the linear function coefficients. Even a change of 0.0001 in the free constant results in a visible deviation from the measured curve. Thus, the most accurate coefficients can be obtained by fitting the cumulative curves.

One can conclude that the observed inflation is completely defined by the labor force change. Hence, there is no other parameter or process, which can potentially disturb this relationship from the inflation side. The two-year delay of the inflation relative to the labor force change is of critical importance. The delay means that all attempts to affect inflation during these years were almost worthless. Real processes in the economic structure of American society are self-consistent, objective and do not depend on 
personal will. Inherent bounds between people in the USA elaborated during a long history of economic interactions are objective and cannot be easily changed by any external force.

The curve displayed in Figure 5 indicates that the participation rate, which defines the evolution of the intensive component of the labor force change, has a strong downward tendency starting from 2001. The linear relationship we have just obtained from the cumulative curve fitting suggests that inflation will decrease. As mentioned above, we are not discussing here the factors controlling the participation rate. So, we cannot predict the overall behavior of inflation yet.

The extensive component of the labor force growth can be predicted with a larger accuracy from the population projections provided by the US Census Bureau [US CB, 2005]. Figure 10 presents the change rate of the projected working age population for the period between 2005 and 2040 and compares the measured labor force and working age population change for the period between 1948 and 2004. As discussed above, the historical data sets demonstrate periods of just the extensive labor force growth (for example, the period from 1990 to 2000).

The extensive component of the labor force growth has a clear drop from 0.01 in 2005 to 0.002 in 2012. This drop is induced by the baby boomers retirement imminent in the near future. The young population cohorts cannot completely replace the boomers in the labor force. Hence, some intensive and quick measures to improve the current participation rate are critical to avoid negative effects. The currently observed tendency of the participation rate change is just the opposite to the desired direction, however.

The linear relationship between the labor force change and inflation allows estimation of the critical value when the inflation reaches zero value. Simple calculations give a rounded value of 0.003 . If participation rate is constant, a deflation period starts from this threshold. Thus, if only the extensive component drop is observed during the next five years, then there is no danger of deflation. The labor force change rate (extensive component) will reach the critical value only in 2012.

Participation rate in the USA was consistently decreasing by 0.0025 between 2000 and 2004. This fact makes the danger of deflation very high right after 2010 if the tendency continues. 
The above consideration does not touch the principal problem of economic growth. Since inflation depends only on some past value of labor force change, one cannot expect real economic growth to affect inflation. And vice versa, no change in economic growth can be induced by inflation - whatever monetary policy is applied (except insane). The observed economic growth is defined by the just one factor - the number of young people of a specific age in the population as found by Kitov [2005a].

\section{Labor force, unemployment and inflation}

As mentioned above, unemployment might represent the people who tried to enter the PID at higher level of income and failed. These people are counted in the labor force. Unemployment is a linear lagged function of inflation during the last twenty years. There was a period of nonlinear behavior, however. This period was characterized by a strong growth in the participation rate, which could potentially induce some nonlinear effects in the unemployment. One can assume that the extensive component growth is a steady process with just very small variations through time. Hence, very weak or no nonlinear effects are expected from the population growth.

The relationship between the rate of the labor force change and inflation is linear during the last forty-forty five years. Hence, all nonlinear processes in the labor force change, like the participation rate growth or decrease, are completely translated into inflation. The unemployment is thus potentially the residual of the inflation and the labor force change. If so, one can obtain an unemployment prediction for the whole period under consideration. This section tests the hypothesis according to the above-developed methodology.

We start with Figure 11 presenting the dynamic evolution of the observed and predicted unemployment in the USA. At this first step, the predicted unemployment is obtained as a linear lagged function of the labor force change only: $U E(t)=0.023+2.1 * d L F(t-6) / L F(t-6)$. The lag of the observed unemployment is six years the value obtained by a simple visual fit of the smoothed curves as presented in Figure 12. There is some discrepancy between the two curves in Figure 11, however. A natural explanation is a low accuracy of the labor force enumeration or presence of some weak nonlinear effects. Figure 13 displays the corresponding cumulative curves for the period 
between 1960 and 2004. The predicted curve is consistent with the observed one during the last 35 years and provides a prediction for the next six years.

We are not using any formal method to reach the best fit between the curves here. The used eye-fit almost reproduces the least squares method, however. Our purpose is not to determine the corresponding coefficients of a regression but to provide a general understanding of the overall dynamic behavior of the variables under investigation. In principle, one can definitely reach a better agreement between the curves by varying the corresponding coefficients. We just demonstrate synchronization of peak and troughs in the observed and predicted curves.

Figure 14 presents a prediction for the unemployment based on the labor force change with the potential nonlinearity compensated by the inflation. The following relationship is obtained:

$$
U E(t)=I N F(t-3)-2.5 *(d L F(t-5) / L F(t-5)-0.0255)
$$

Here the "neutral" value of the labor force change rate is 0.0255 . The lags are three years for the inflation (we can choose between 2 and three years since the central value is 2.5 years) and five years for the labor force change. The inflation is represented by the GDP deflator. Figure 15 and 16 depict the corresponding smoothed by averaging in 7-year moving window and cumulative curves used to estimate the above coefficients. There are some weak deviations (approximately $0.5 \%$ ) between the smoothed curves in the mid1990s. The overall agreement is almost the same as for the labor force change only, as presented in Figures 11 through 13.

Figures 17 through 19 illustrate some results obtained where the CPI represents the inflation. The corresponding relationship is very close to that obtained for the GDP deflator with the same lags:

$$
U E(t)=\operatorname{INF}(t-2)-2.5 *(d L F(t-5) / L F(t-5)-0.0234) .
$$

These relationships provide a prediction of the unemployment for the next two to six years.

Fortunately, this is not the whole story. Methodology and technique for the inflation and labor force measurements can easily be improved. This is a standard situation in natural sciences when some general form of a relationship is found and only a relative improvement of description and prediction is sought. Actually, all fundamental 
physical laws are obtained by this procedure with an ultimate demand of improvement of the overall match of the measured and predicted values diminishing with increasing accuracy of measurement.

\section{Discussion and conclusions}

There is almost nothing to discuss because the findings are orthogonal to the current theories and monetary policy. Many concepts related to business cycles and dependence between inflation and unemployment are currently considered to be valid. As a rule, they are denied by the empirical evidences presented in this paper. The author does not intend to recommend anything specific to the central bankers and monetary economists other than consider these results during their routine business. Some important changes expected to surface in the next five to seven years including deflation will need attention. At the same time, the relationships obtained in this study are not accurate enough to be used in economic theory and practice as they are now. Massive efforts are needed to refine the unemployment, inflation and labor force readings in order to obtain precise coefficients of the linear (or weakly nonlinear) relationships predicting the evolution of the variables of interest. Potential outcomes, however, cannot be exaggerated - accurate knowledge of the future evolution of key social and financial parameters unemployment and inflation. Moreover, a reasonable social policy associated with the labor force control is a straightforward requirement.

In order to confirm the general findings of this study we have conducted a similar study for France and Austria. These two countries present examples of intermediate- and small-size economies in terms of their labor forces. All the above relationships are confirmed. The lag times between the labor force change, inflation and unemployment are different: six years in France and one year in Austria. The labor force changeinflation elasticity in France is very high - 15. In Austria, the elasticity is low - 2.2. The high elasticity in France makes the accuracy of the labor force measurements of critical importance - strong fluctuations are observed. The predicted curves, smoothed and cumulative, are in better agreement with the observed ones. In Austria, the annual readings are also well predicted.

To conclude we repeat briefly the principal findings of the study: 
- The driving force for inflation in the USA is the labor force change. The inflation lags two and a half years behind the labor force change.

- Unemployment is a lagged linear function of the labor force change and inflation with lag times of six and three years respectively.

- Stagflation and decreasing inflation (disinflation) accompanied by decreasing unemployment are just natural results of the lag and the dependence of the inflation and unemployment on the labor force change.

- One can forecast inflation and unemployment two to six years ahead.

- The population projections constructed by the US Census Bureau provide a useful tool to evaluate the long-term behavior of the labor force changes. The current period of disinflation will probably transform into deflation starting 2010-2012.

- Inflation and real economic growth are independent and driven by different forces related to population.

\section{Acknowledgements}

The author is grateful to Dr. Wayne Richardson for his constant interest in this study, help and assistance, and fruitful discussions. The manuscript was greatly improved by his critical review. 


\section{References}

Ball, L., N.G.Mankiw, (2002) “The NAIRU in Theory and Practice”, Journal of Economic Perspectives, v. 16, n. 4, pp.115-136.

Kitov, Ivan, (2005a) GDP growth rate and population, Research Announcements, Economics Bulletin, Vol. 28 no. 9 p. 1.

Kitov, I. O., (2005b) "A model for microeconomic and macroeconomic development," Working Papers 05, ECINEQ, Society for the Study of Economic Inequality

Mankiw, N.G., (2000) “The Inexorable and Mysterious Tradeoff between Inflation and Unemployment”, Harvard Institute of Economic Research, Discussion paper n. 1905, Harvard University, Cambridge , Massachusetts. http://post.economics.harvard.edu/hier/2000papers/2000list.html

U.S. Census Bureau, (2002) Technical paper 63RV, "Current Population Survey Design and Methodology”, http://www.census.gov/prod/2002pubs/tp63rv.pdf http://www.census.gov/ipc/www/usinterimproj/usproj2000-2050.xls

U.S. Census Bureau, (2005) Table, “ U.S. Interim Projections by Age, Sex, Race and Hispanic Origin”, Detail file, Last Revised August 26, 2004, http://www.census.gov/ipc/www/usinterimproj/usproj2000-2050.xls

U.S. Department of Commerce, Bureau of Economic Analysis, (2005) Table, "Current-Dollar and "Real" Gross Domestic Product (Seasonally adjusted annual rates)", 12.21.2005, http://bea.gov/bea/dn/gdplev.xls

U.S. Department of Labor, Bureau of Labor Statistics, (2005a) Table, "Labor Force Statistics from the Current Population Survey”, 12-15-2005, http://data.bls.gov/cgibin/surveymost?ln

U.S. Department of Labor, Bureau of Labor Statistics, (2005b) Table, “Consumer Price Index, All Urban Consumers”, 12-15-2005, ftp://ftp.bls.gov/pub/special.requests/cpi/cpiai.txt

U.S. Department of Labor, Bureau of Labor Statistics, (2006). "The Employment Situation: January 2006”, 02/03/2006, http://www.bls.gov/news.release/archives/empsit_02032006.pdf 


\section{Figures}

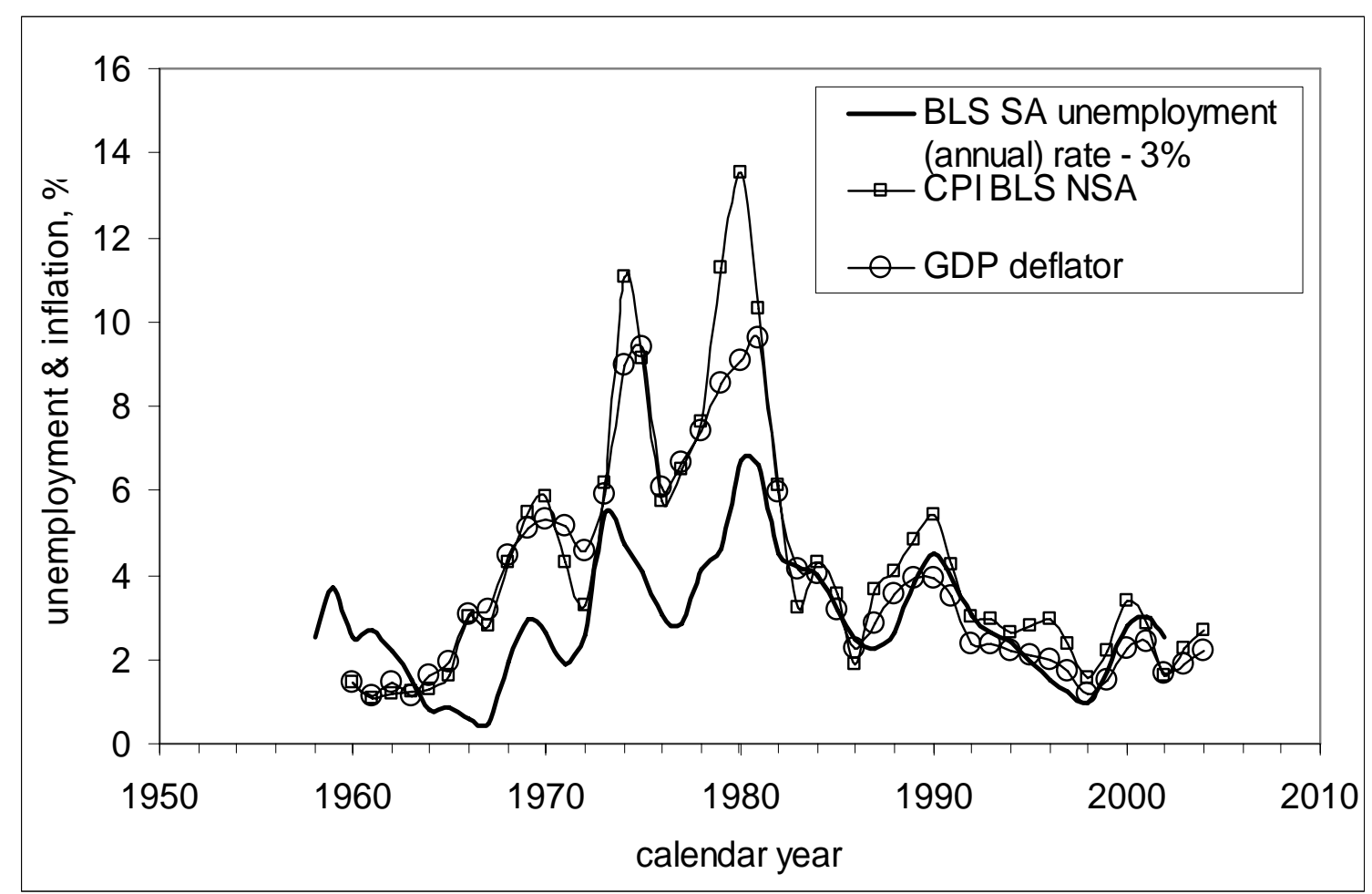

Fig. 1. CPI, GDP deflator and unemployment rate. The unemployment is reduced by $3 \%$ in order to equalize it with inflation after 1985 and is shifted 2.5 years back to synchronize the peaks and troughs through the studied period. One can observe a clear synchronization of the curves after 1965 with varying amplitude of fluctuation, however. Curves serve to construct modified Phillips curves. 


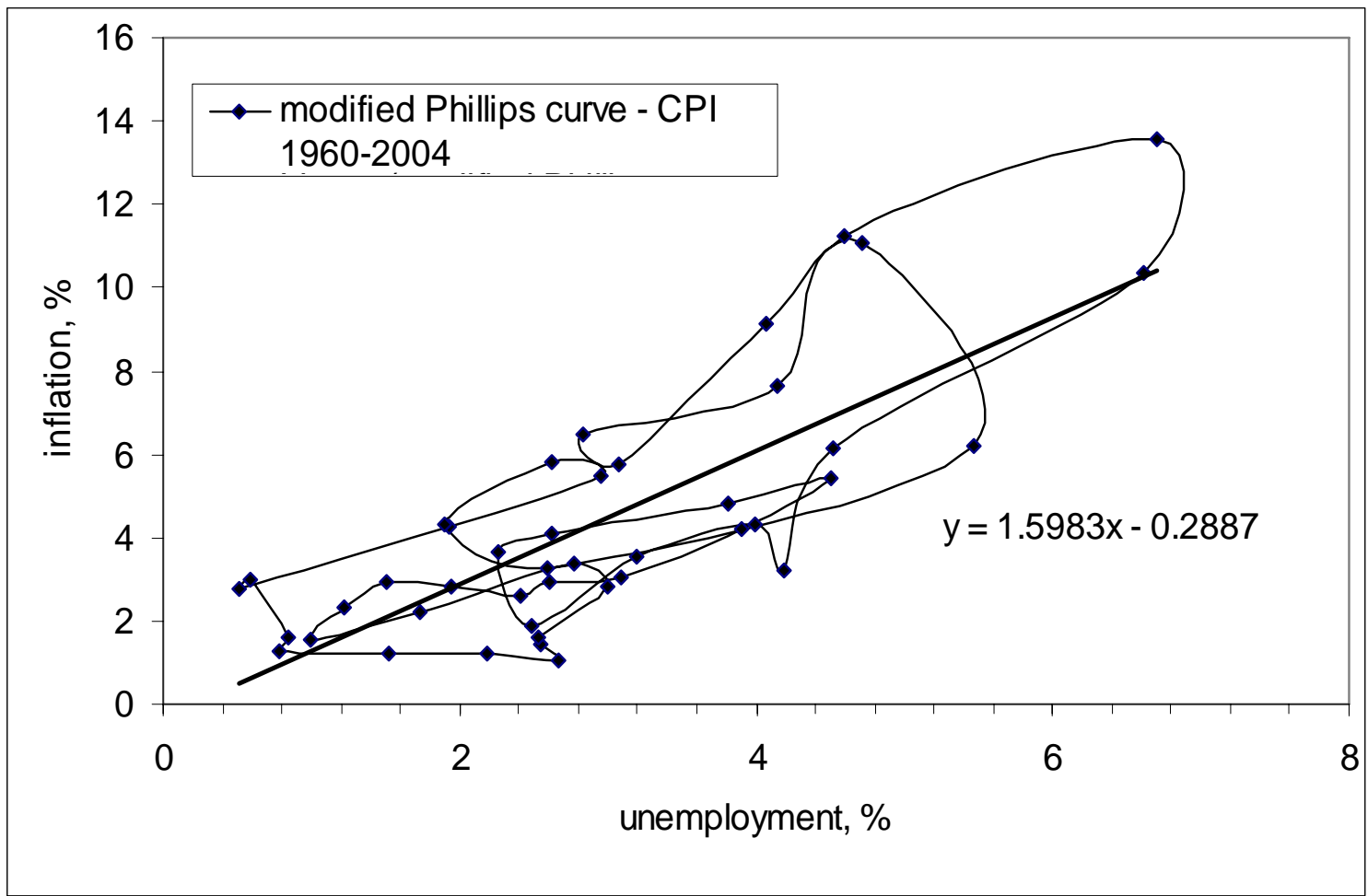

Fig. 2. Modified Phillips curve (CPI-unemployment) for the period between 1960 and 2004. The unemployment readings are shifted 2.5 years back. A clear linear dependence is observed with just some short periods of orthogonal behavior IN the relationship. Two principal conclusions can be derived:

- the causality principle denies the possibility the unemployment affects the inflation;

- the same principle excludes current economic growth dependence on unemployment rate because the latter is only a function of inflation 2.5 years before. 


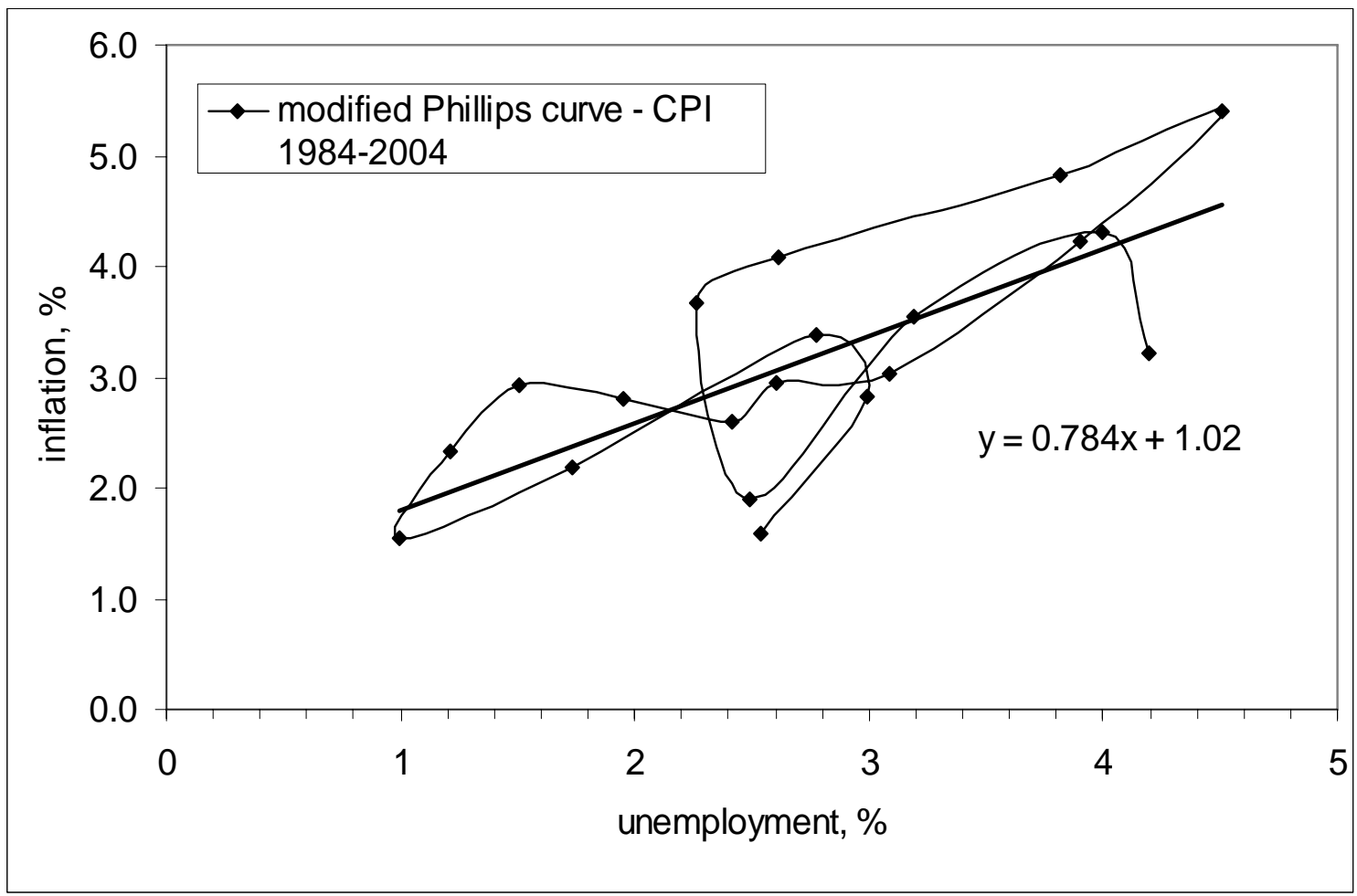

Fig. 3. Modified Phillips curve (CPI-unemployment) for the period between 1984 and 2004. The unemployment is shifted 2.5 years back. A clear linear dependence is observed with just short periods of orthogonal behavior in the relationship, which might be related to frequent modifications of the unemployment and CPI measuring procedures and definitions. The linear regression coefficient is 0.78.This coefficient differs from that characterizing the period between 1960 and 2004 which is equal to 1.6. This implies the existence of periods with lower sensitivity of unemployment to inflation. The difference is explained by changes in labor force growth rate over the period. 


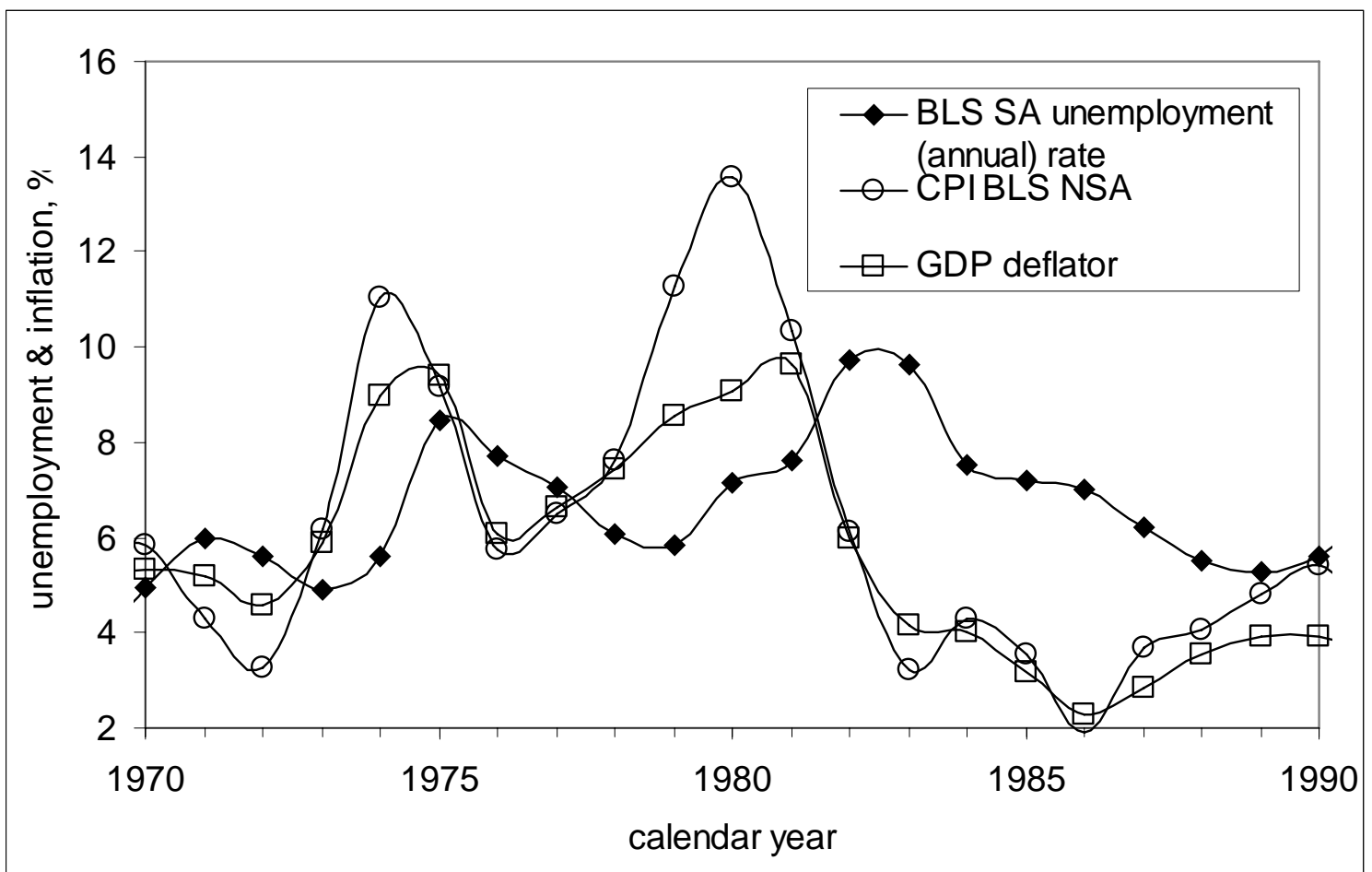

Fig. 4. Unemployment, CPI and GDP deflator between 1970 and 1990 in the USA. The curves demonstrate the stagflation effect induced by the unemployment lag behind the inflation. 


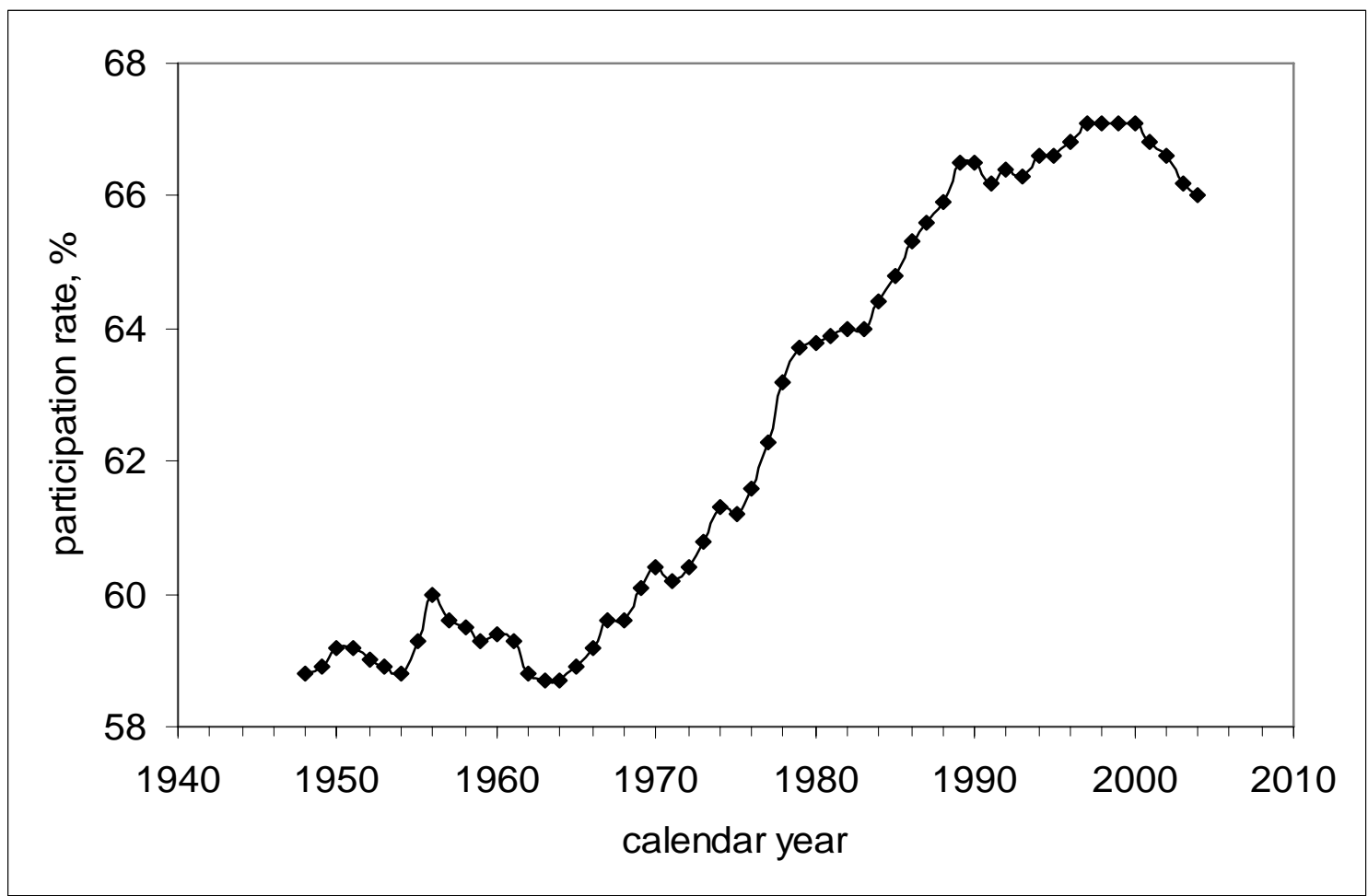

Fig. 5. Evolution of participation rate in the USA between 1948 and 2004. The rate grew from $60 \%$ in the late 1960 s to almost $67 \%$ in 1990 . There were periods of very fast growth in the late 1970s and 1980s with a flat part between 1979 and 1984. There is a downward tendency observed after 2000. 


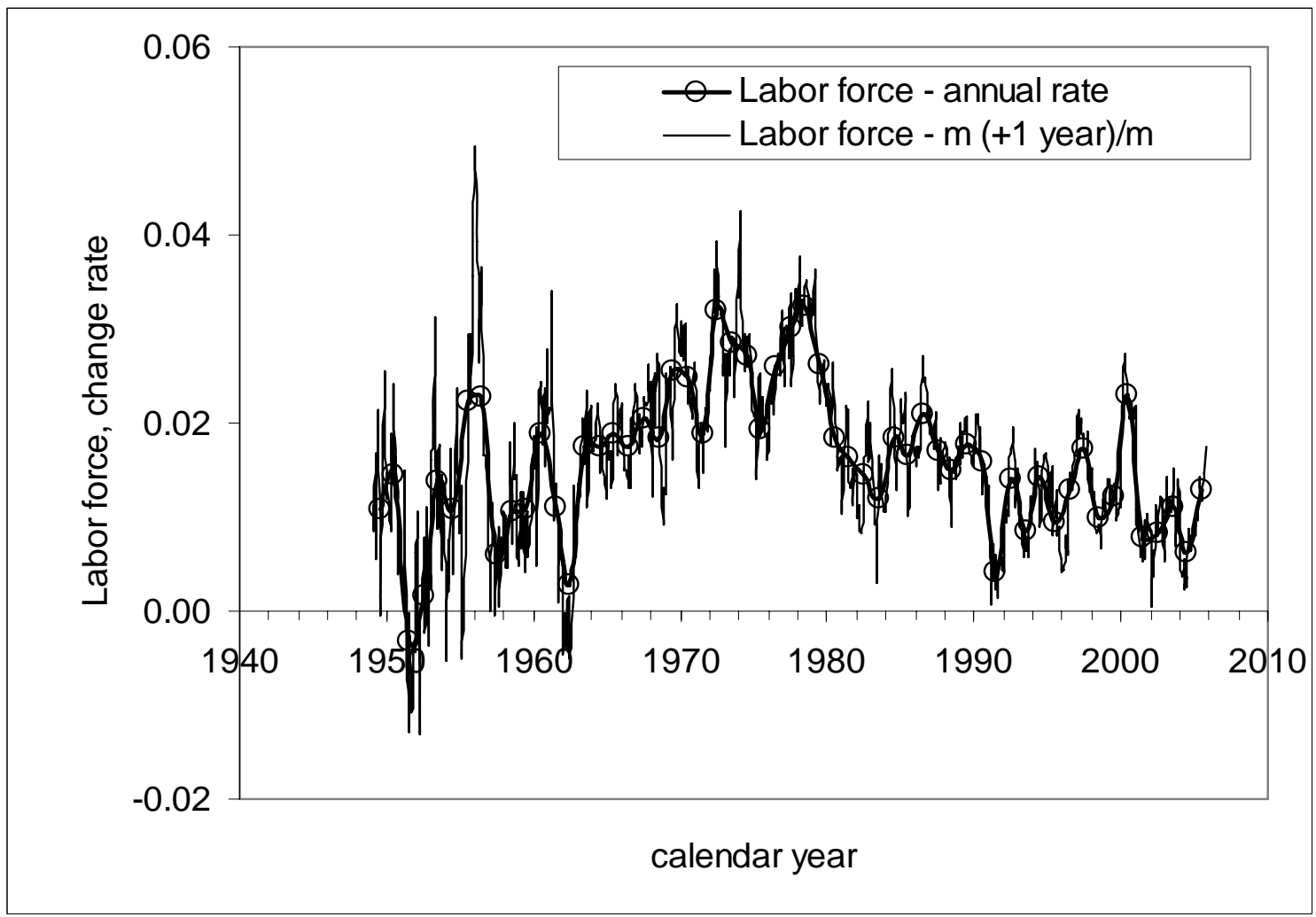

Fig. 6. Labor change rate between 1947 and 2004: annual rate and month-on-month (m/m) a year before rate. The average annual value over the years is 0.0159 . The highest $\mathrm{m} / \mathrm{m}$ rate was observed in the middle 1950s. Two sharp and high peaks in annual rate correspond to the periods of high inflation. Starting the early 1980s, the labor force change rate is near and below 0.02 except for a peak around 2000. One can link the peak to the population correction induced by the "closure error", when the postcensal total population estimate by the US Census Bureau was increased by about 4.5 million after the census. The same effect might also induce artificial sharp changes in the published labor force figures near the census years. 


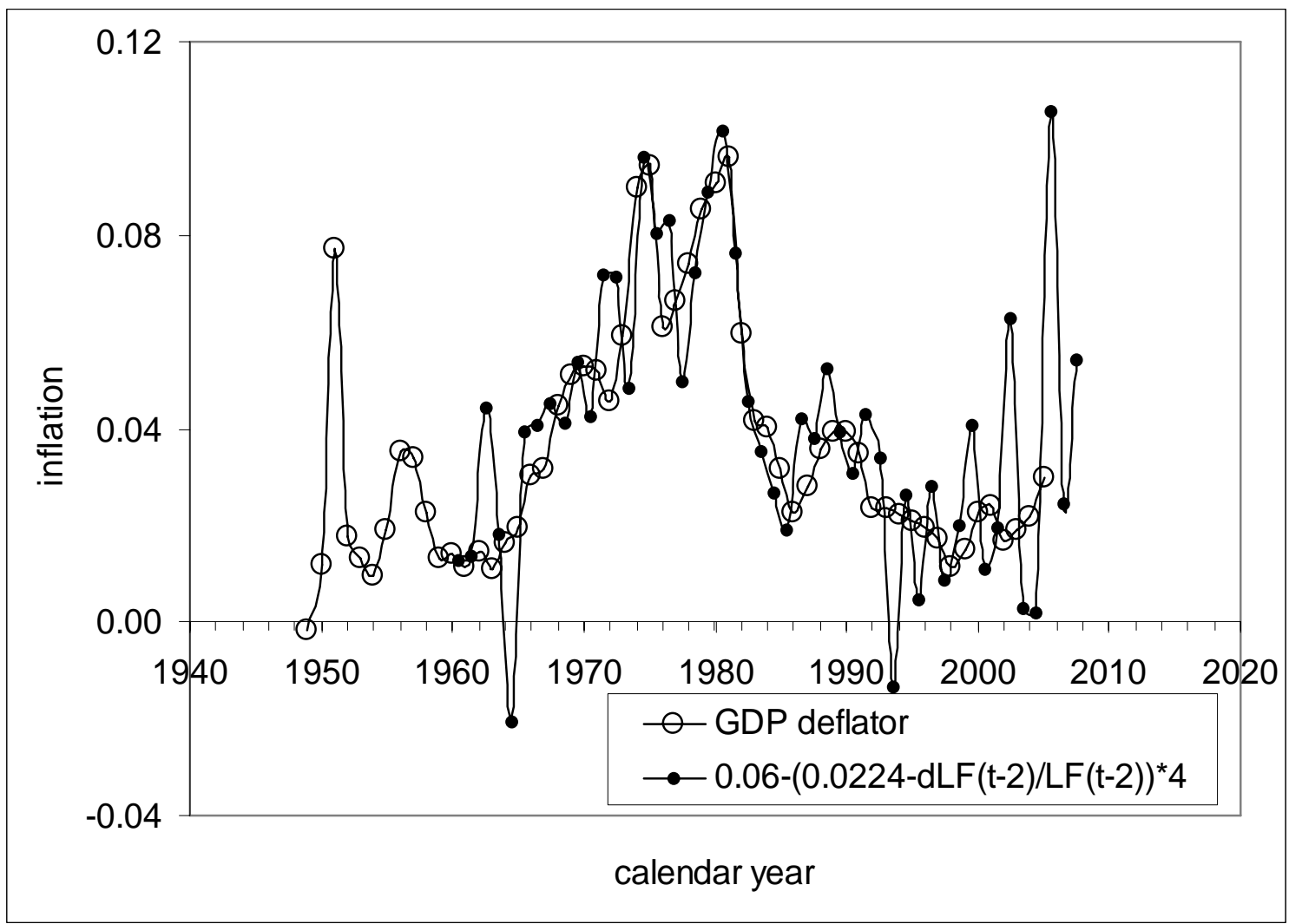

Fig. 7. The observed inflation (GDP deflator) and the predicted from the labor force change rate (shifted 2.5 years ahead). An agreement is observed throughout the whole period with just some short fluctuations in labor force potentially induced by the population corrections implemented by the Census Bureau in the census years. 


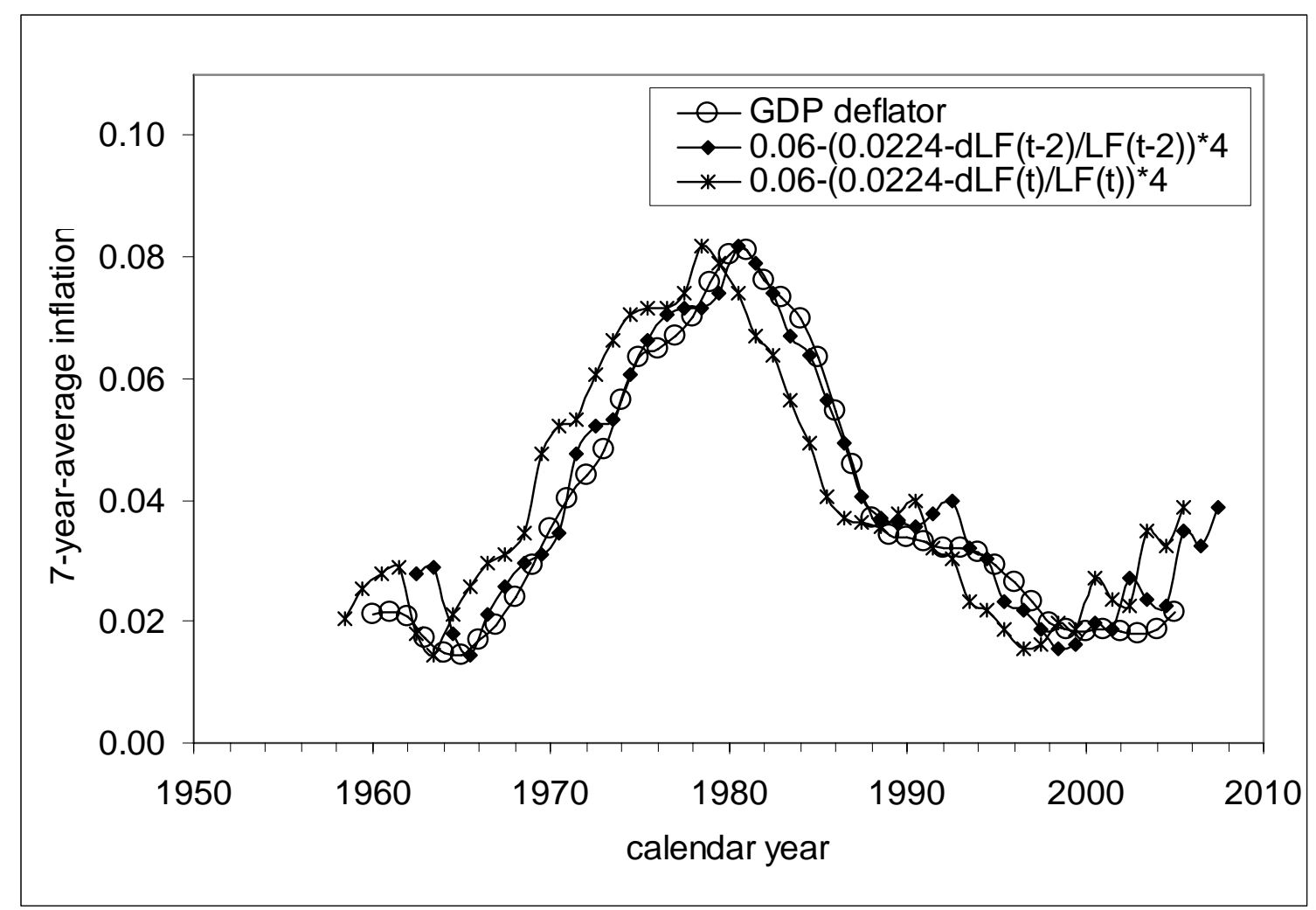

Fig. 8. Comparison of 7-year moving window averages for the predicted and measured inflation. The prediction is made according to the relationship INF $=4 *(\mathrm{dLF} / \mathrm{LF})-0.03$. The predicted curve is shifted by 2.5 years ahead in time in order to fit the peak value near 1978. The effects of the population correction are clear near the census years. The last two corrections were particularly large. 


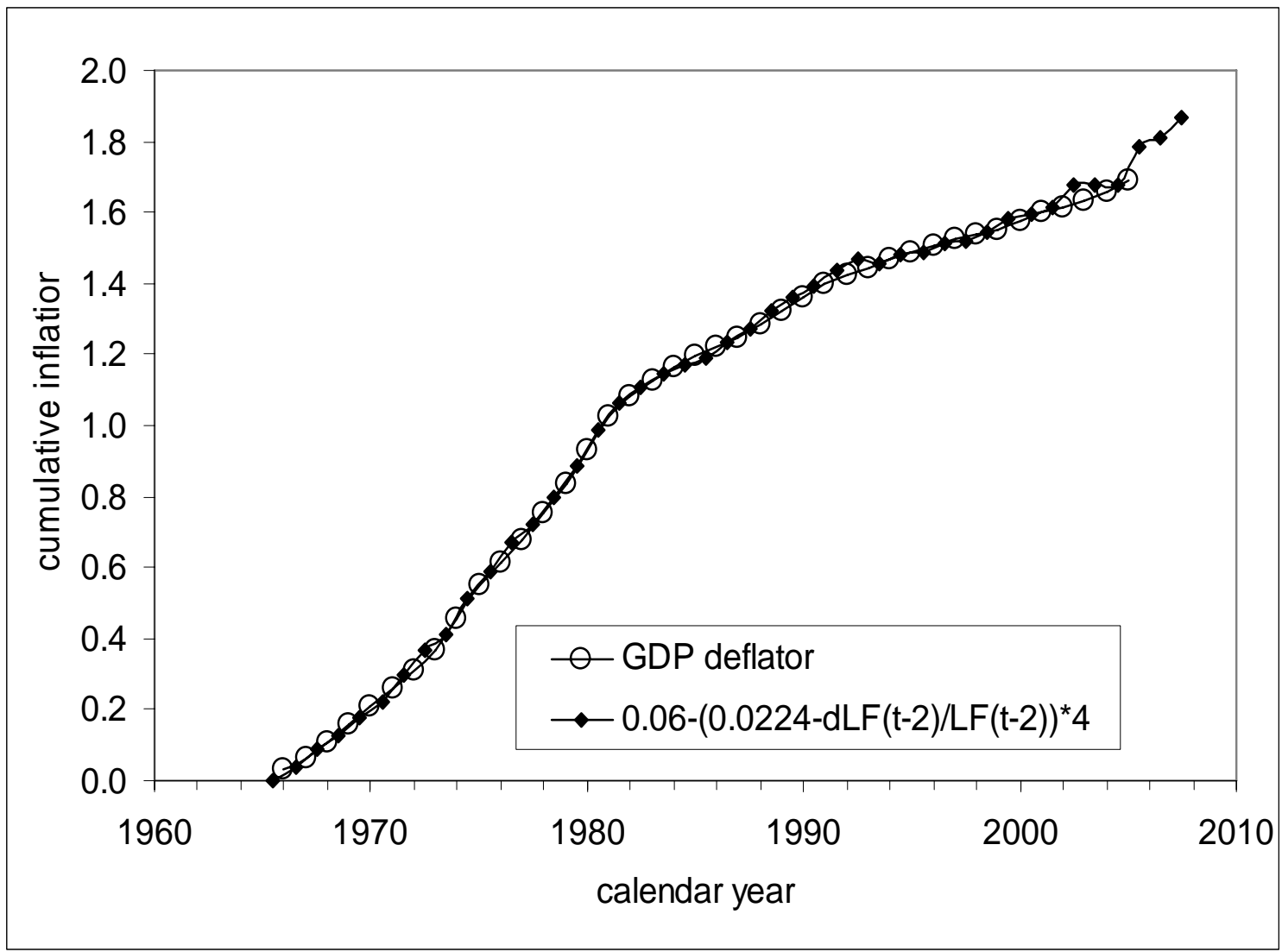

Fig. 9. Comparison of the cumulative values of the observed and predicted inflation presented in Fig. 7. The predicted curve starts from 1963 and is shifted by 2.5 years ahead. An agreement is observed with a notable change from a convex portion before 1980 to a concave one after 1980. In the long run, one can expect a decreasing labor force change rate and corresponding low inflation rate. 


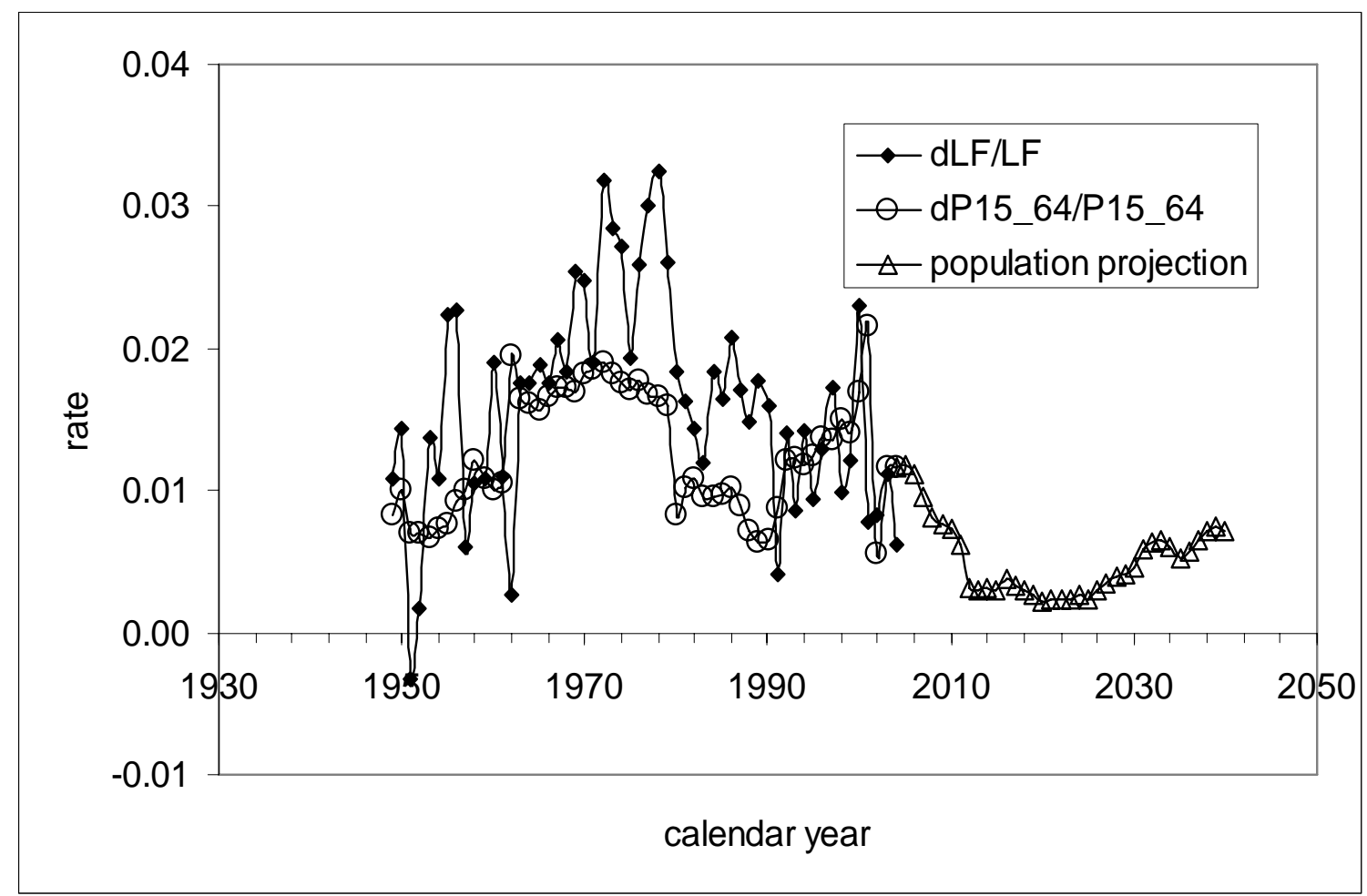

Fig. 10. Comparison of the labor force and working age population change for the period between 1948 and 2004 and projection of the working age population change until 2040. Corrections for the "closure error" between the postcensal estimates and census enumerations are clear as steps and bursts in the otherwise smooth curve. The projected working age population growth rate will suffer a severe drop from the current value of 0.01 to a very low value of 0.003 in 2012 and an even lower value of 0.002 in 2020. 


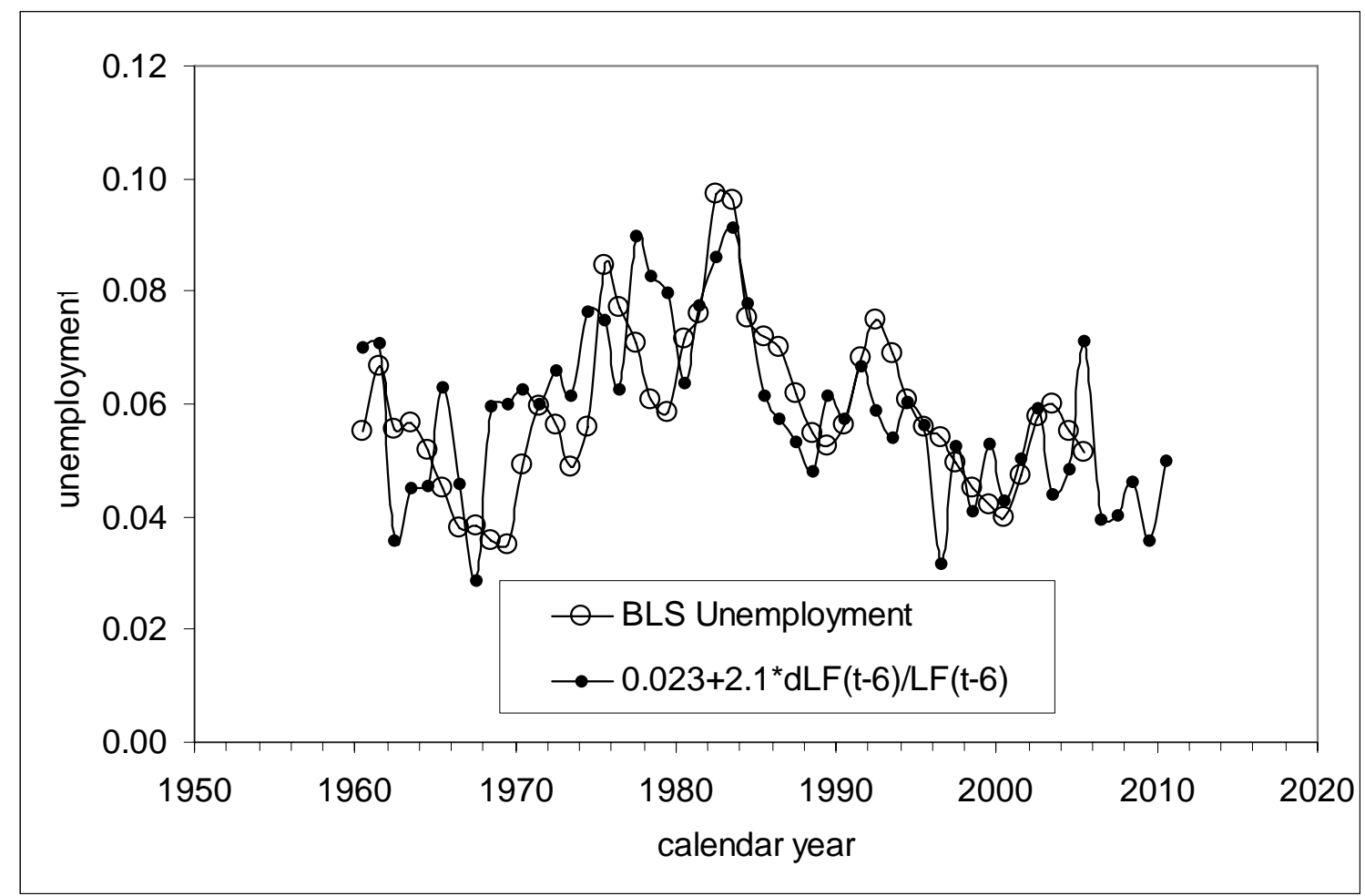

Fig. 11. The observed and predicted by the labor force curves for unemployment rate in the USA between 1960 and 2004. The labor force change rate is reduced to 0.024 and multiplied by 2.1 in order to correct for the difference in absolute change of the unemployment and labor force. The value 0.06 is the mean unemployment value for the period between 1948 and 2004. The lag is about 5 years. 


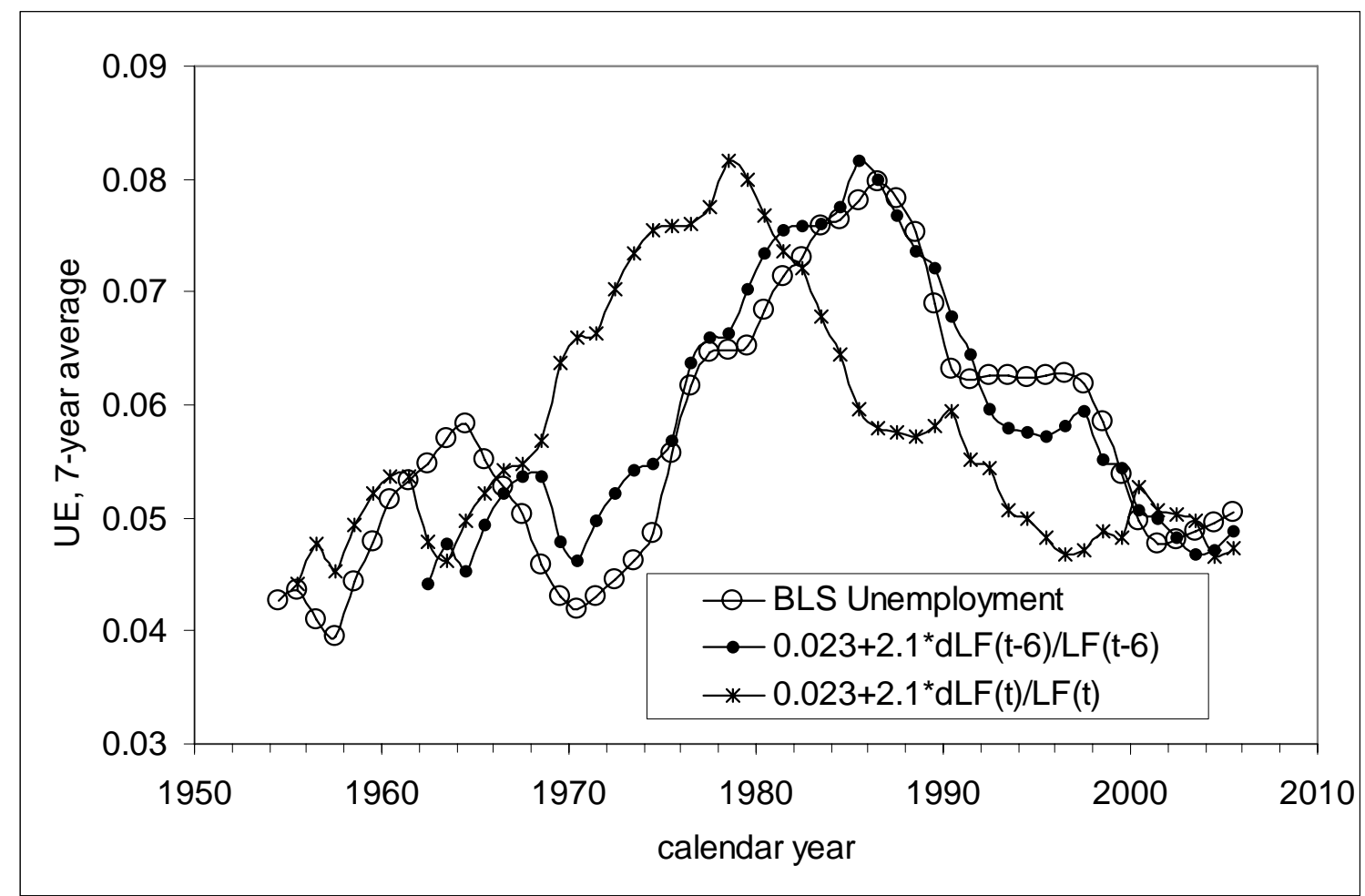

Fig.12. The predicted and observed unemployment rate smoothed by averaging in 7-year-wide moving windows. The original predicted curve and that shifted by six years back are presented in order to illustrate synchronization process and the lag time estimation. 


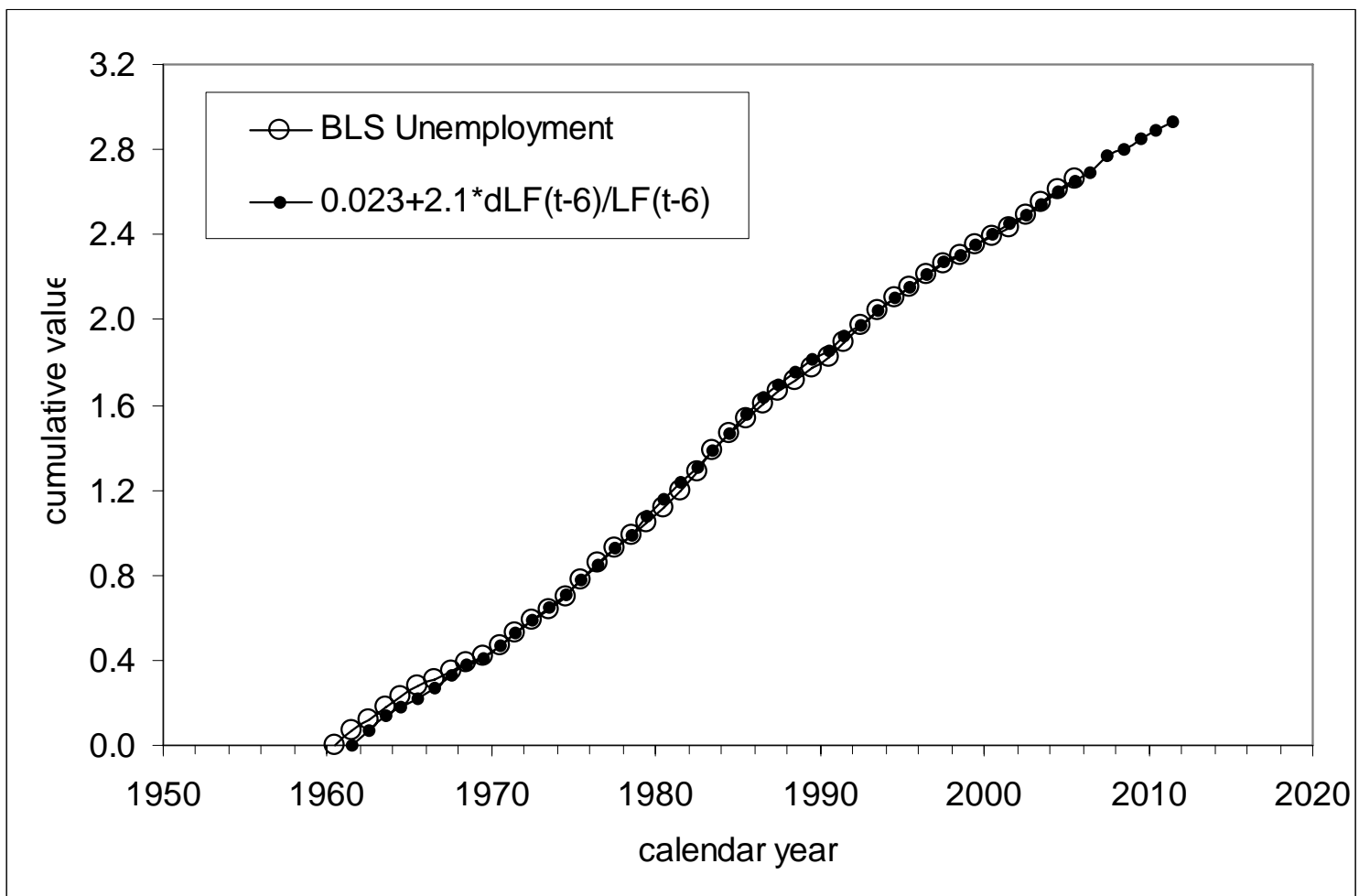

Fig. 13. Cumulative behavior of the observed and predicted unemployment in Fig. 11. 


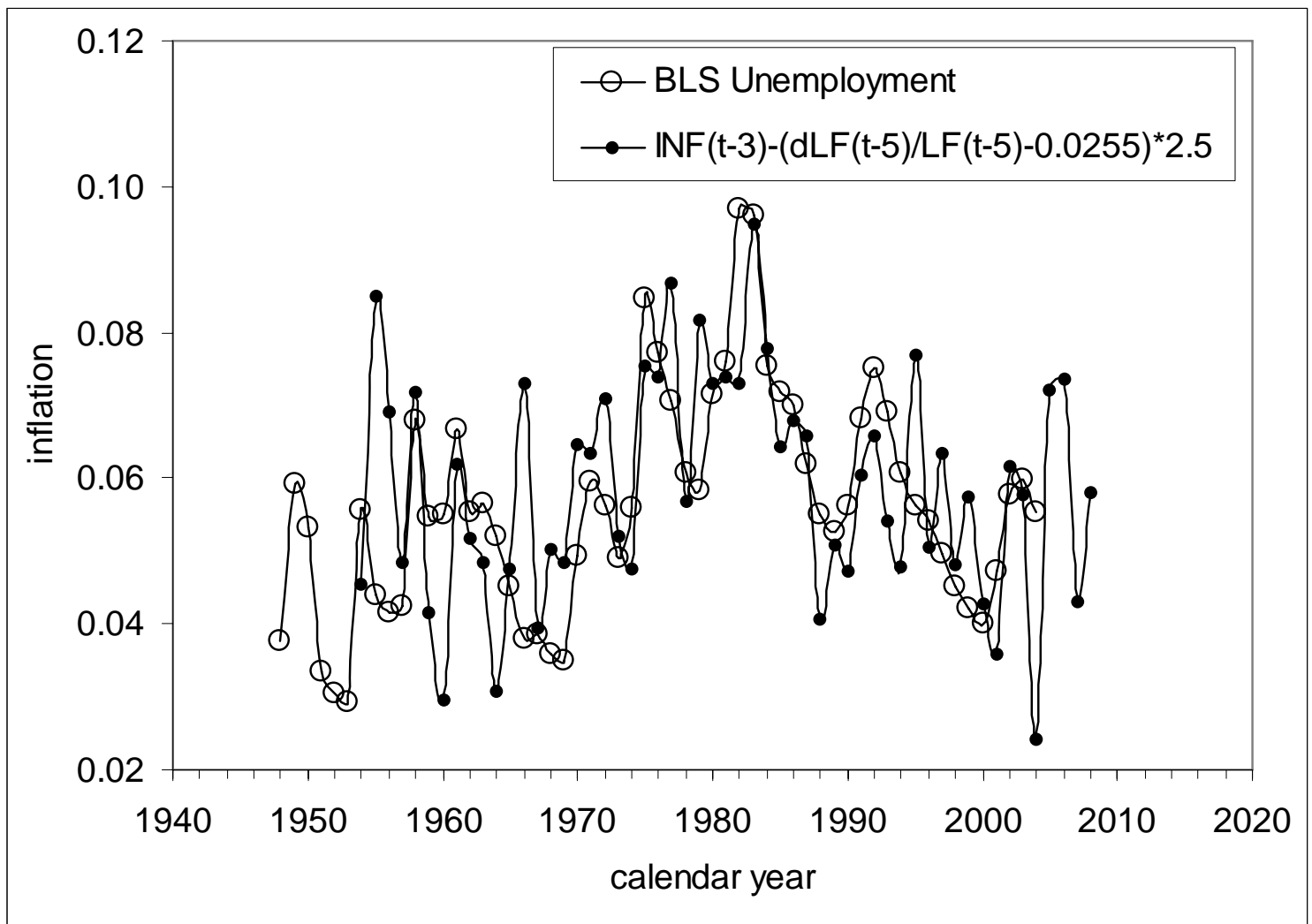

Fig. 14. The observed unemployment (UE) and the unemployment predicted as a lagged linear function of labor force change rate (dLF/LF) and inflation (INF - GDP deflator). The inflation readings are shifted three years back and those for the labor force by five years back in order to fit the observed peaks and troughs. A three year prediction is available and indicates a short term unemployment increase in the next two years. 


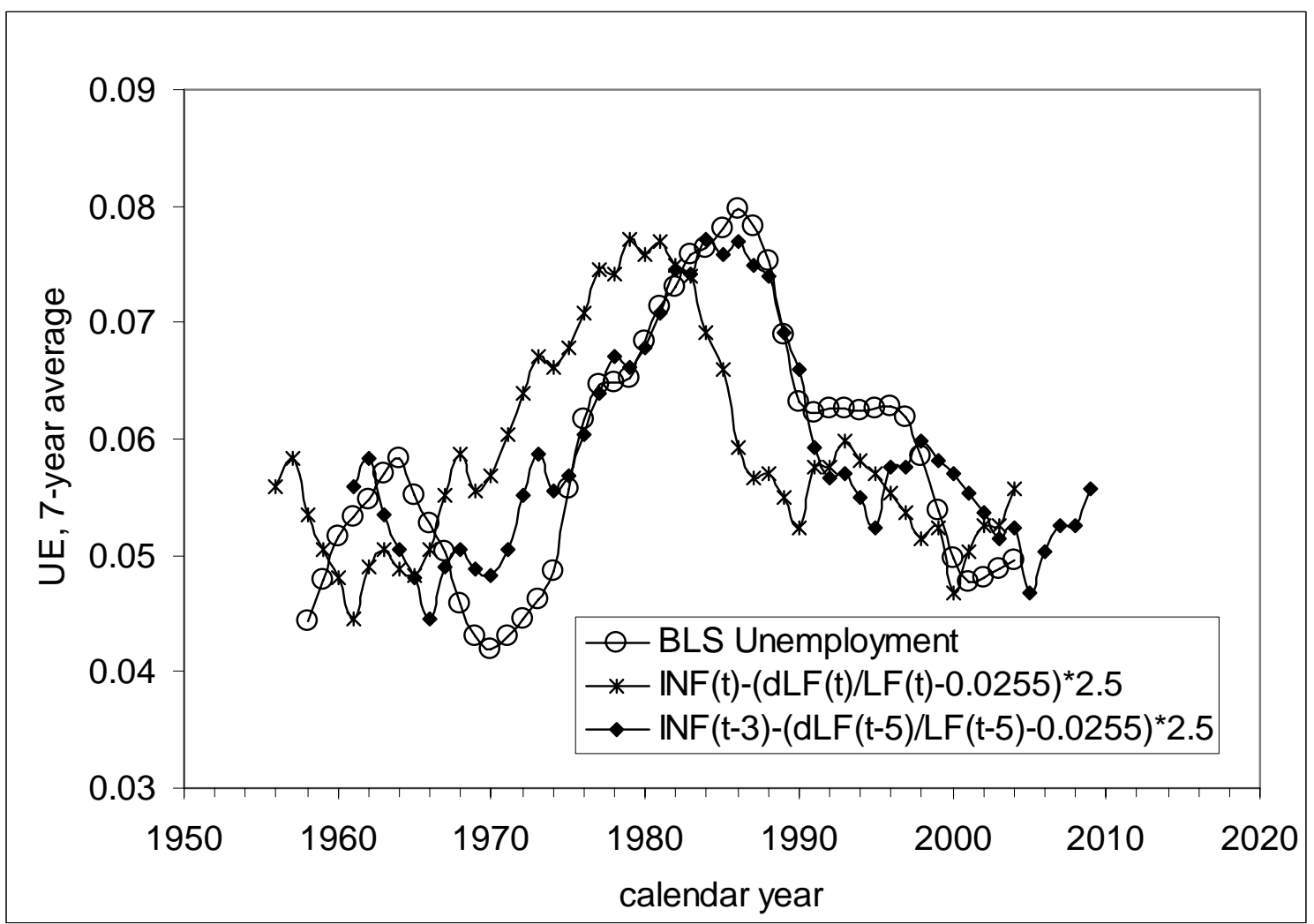

Fig. 15. Same as in Fig. 14 but smoothed by averaging in 7-year-wide moving windows. 


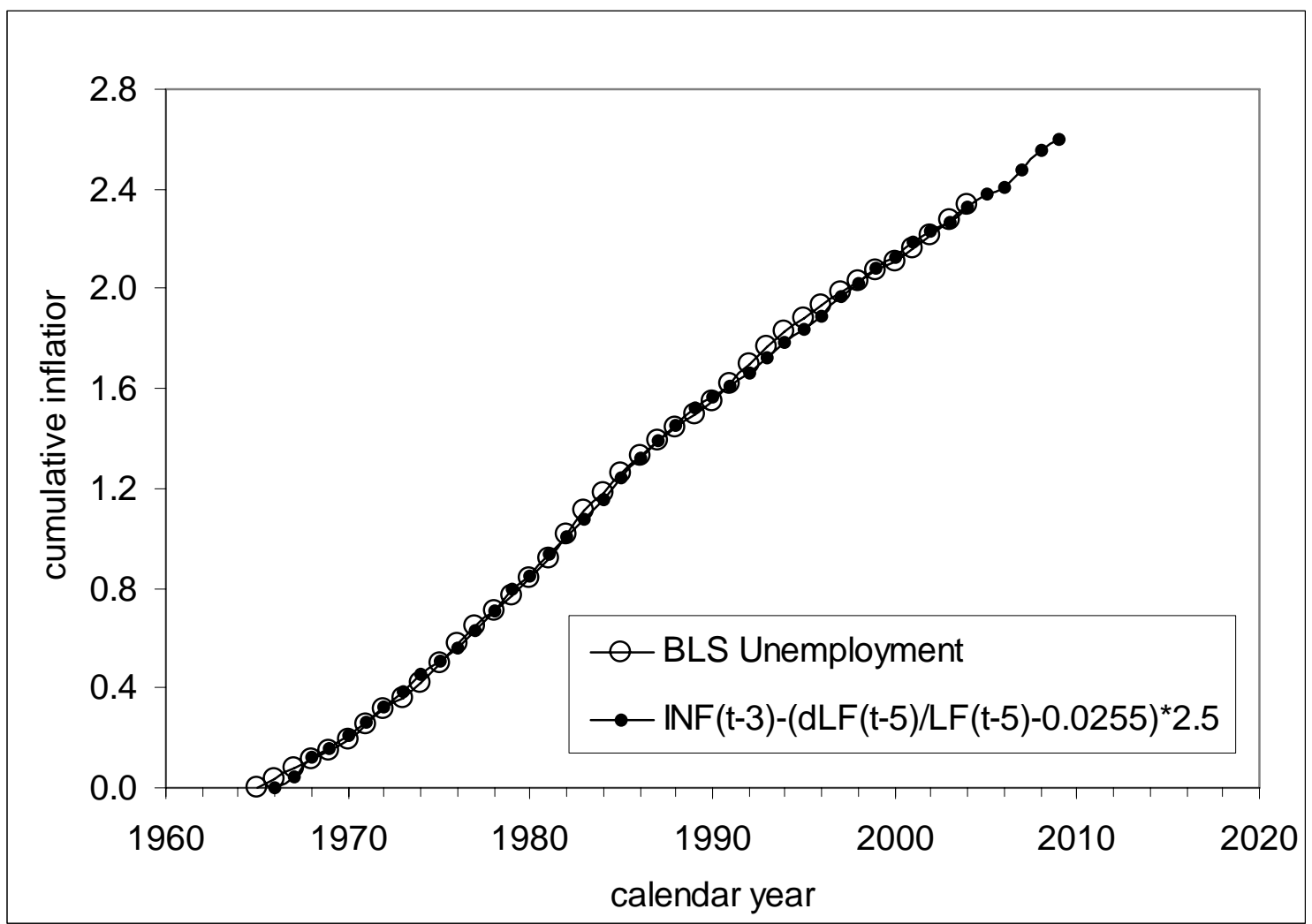

Fig.16. Cumulative behavior of the observed and predicted unemployment in Fig. 14. 


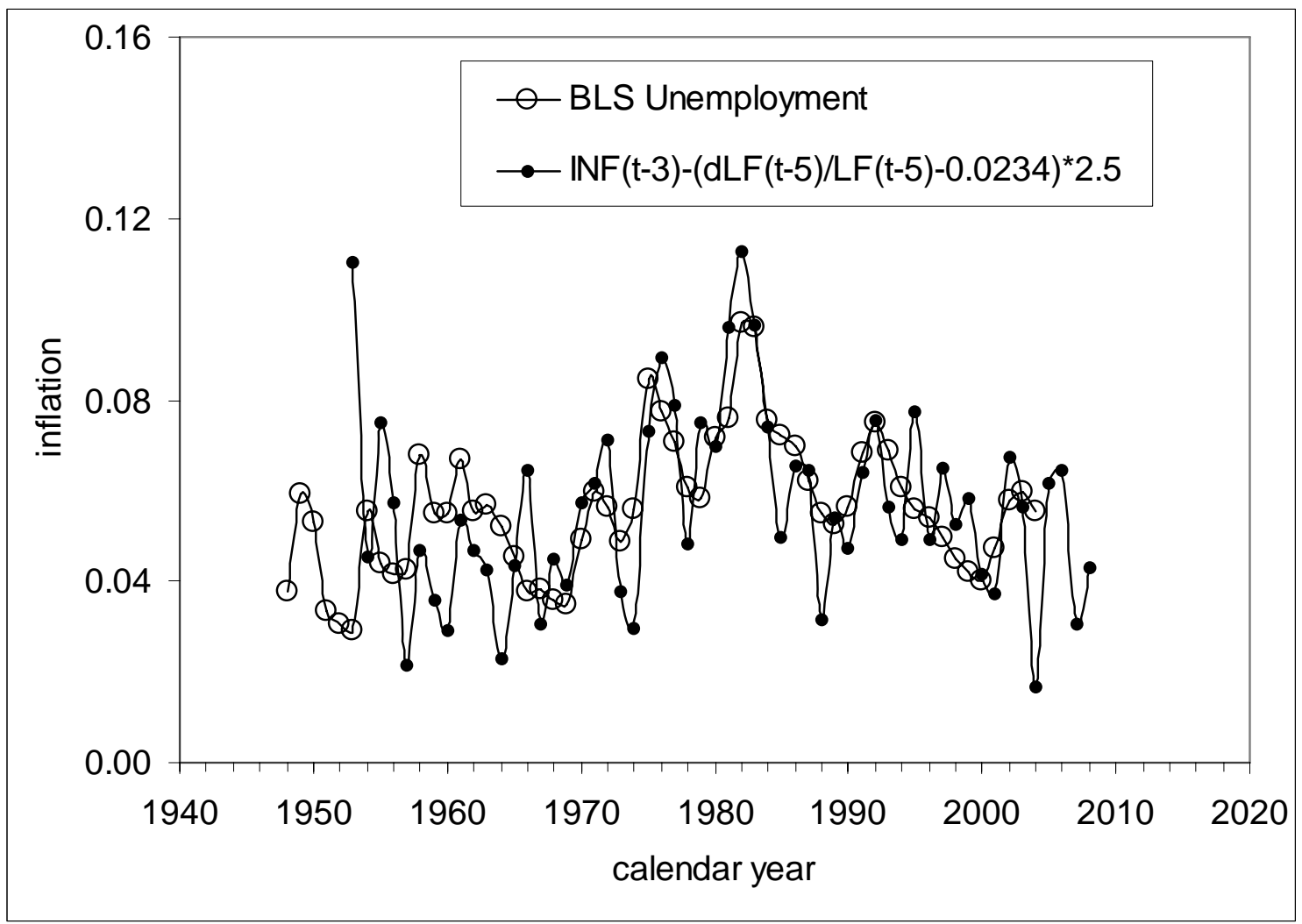

Fig. 17. The observed unemployment (UE) and the unemployment predicted as a lagged linear function of labor force change rate (dLF/LF) and inflation (INF - CPI). 


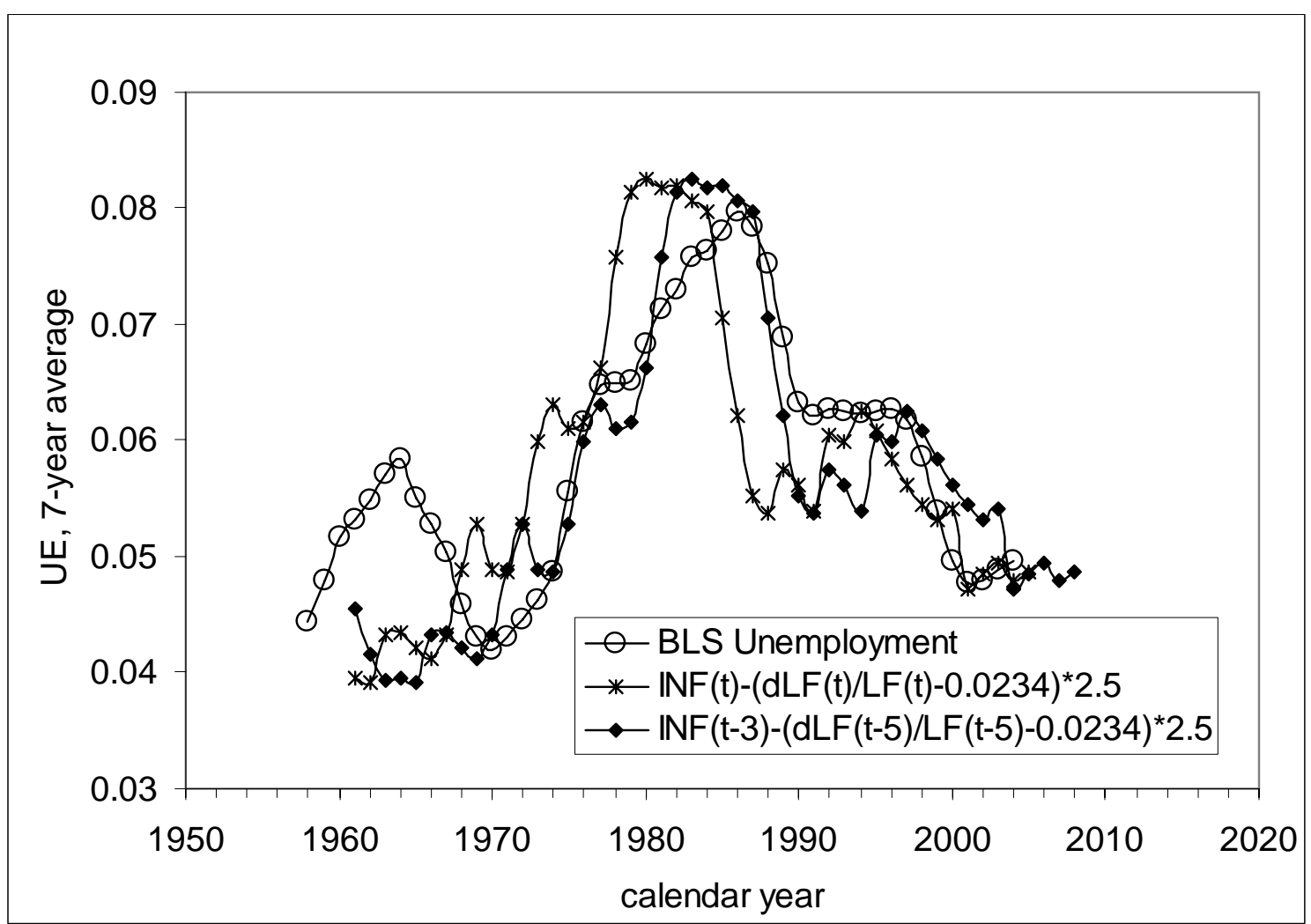

Fig. 18. Same as in Fig. 17 but smoothed by averaging in 7-year-wide moving windows. 


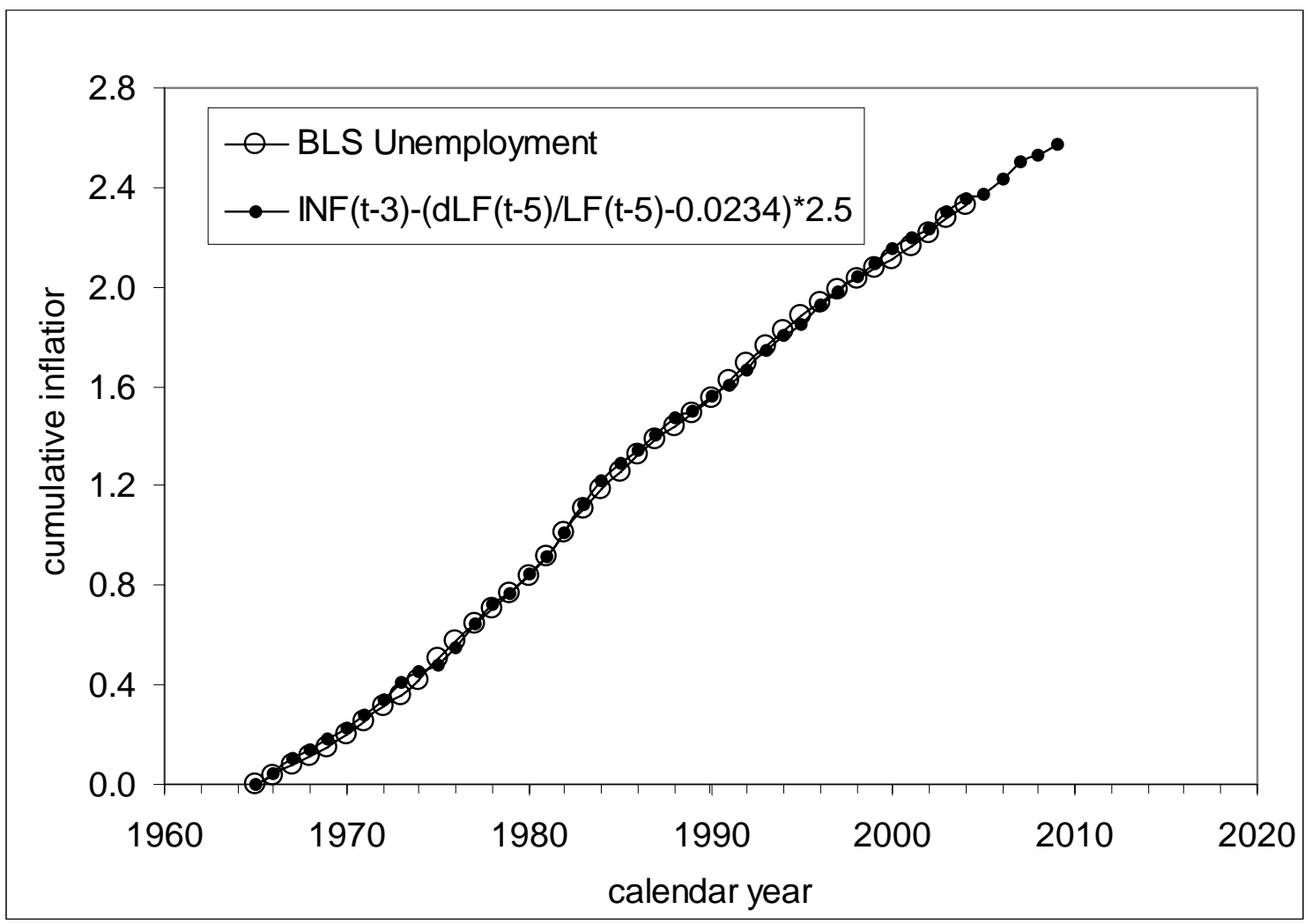

Fig.19. Cumulative behavior of the observed and predicted unemployment in Fig. 17. 